\title{
Submucosal tunneling endoscopic resection of a gastric gastrointestinal stromal tumor
}

A 64-year-old man was admitted to our hospital for endoscopic resection of a gastrointestinal stromal tumor (GIST) of the gastric antrum.

The submucosal tumor had been previously observed during an esophagastroduodenoscopy, which revealed a protruded lesion in the greater curve of the gastric antrum. The subsequent endoscopic ultrasound showed that the tumor was large $(20 \mathrm{~mm})$, arose from the muscularis propria layer, and showed a persistent enhancement after infusion of SonoVue (Bracco, Milan, Italy). The contextual fine-needle aspiration, performed with a 19 gauche Echotip Ultra (Cook Medical Inc. Limerik, Ireland), showed solid clusters of spindle cells, which were positive for CD34 and CD117, and therefore diagnostic for GIST.

On this basis, a submucosal tunneling endoscopic resection (STER) was performed with a HybridKnife T-Type (ERBE, Tubingen, Germany) and IT-Knife 2 (Olympus, Tokyo, Japan). A submucosal tunnel was created through a longitudinal incision of the mucosal layer. After reaching the tumor, the lesion was carefully dissected from the layers of the gastric wall and subsequently removed ( $\mathbf{F i g} \mathbf{1} \mathbf{1} \mathbf{a}, \mathbf{b}$ ). At the end of the procedure, the mucosal defect was closed with Instinct clips (Cook Medical Inc.) (\Fig.1 c). The STER procedure was completed, without adverse events, in about 150 minutes ( $>$ Fig.1 d, $>$ Video 1 ).

The histopathological examination showed a low risk GIST [1] that was positive for smooth muscle actin, CD34, and CD117, and negative for S-100 protein. The mitotic activity was 1 mitoses per 50 HPF ( Fig. 2).

The patient was discharged after three days uneventful, and was referred for endoscopic follow-up. The endoscopic and echoendoscopic follow-up performed after 1 year did not reveal any residual or recurrent tumor.

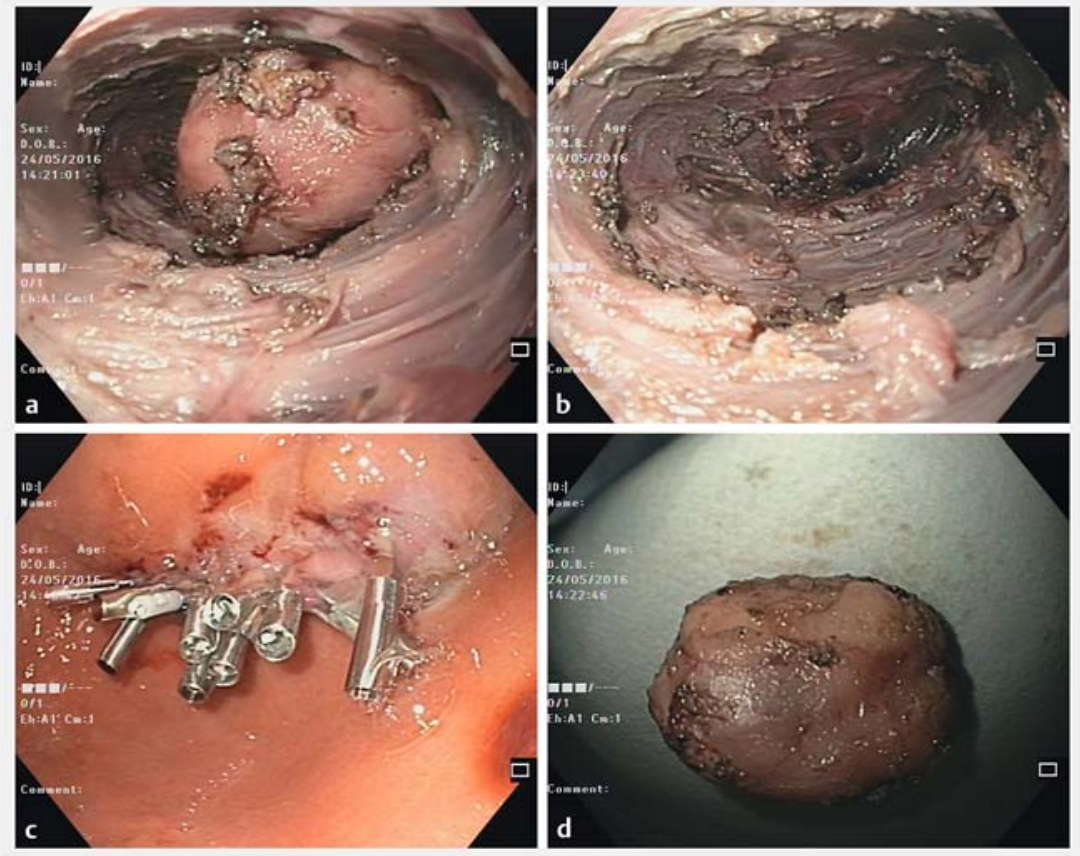

- Fig. 1 Submucosal tunneling endoscopic resection. a Peritumoral dissection. b The tunnel after removal of the submucosal tumor. c Closure of the proximal mucosal defect with clips. d The gastrointestinal stromal tumor after removal.

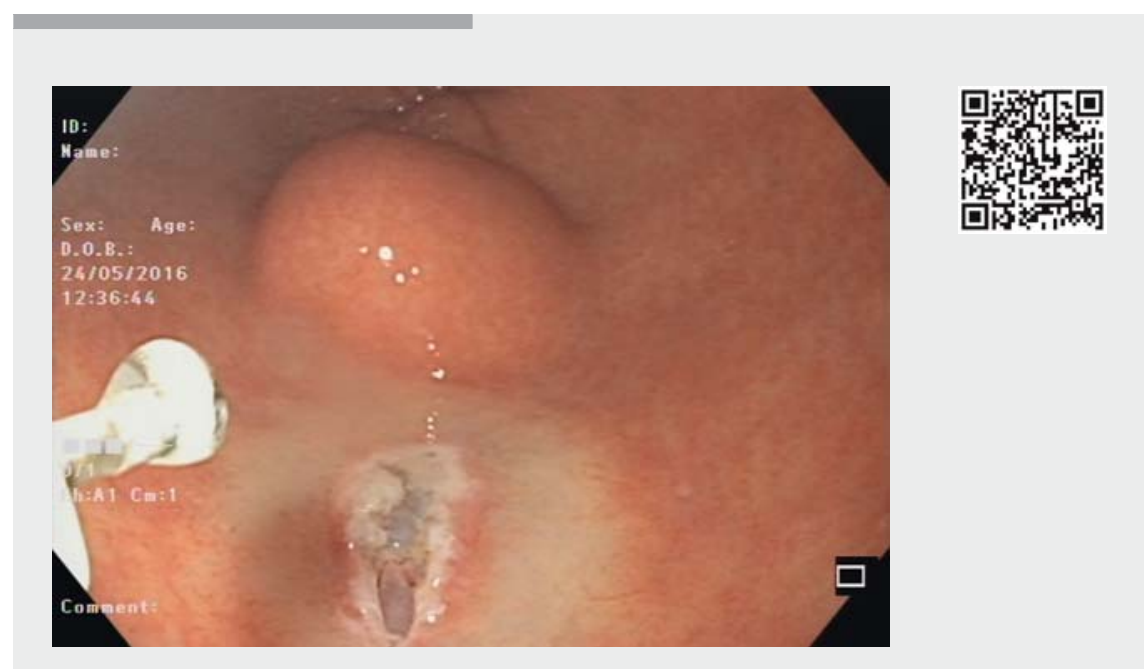

$\checkmark$ Video 1 The submucosal tunneling endoscopic resection was performed using two types of diathermic knives. After reaching the tumor the lesion was dissected and removed. At the end of the procedure the mucosal defect was closed with metallic clips. 


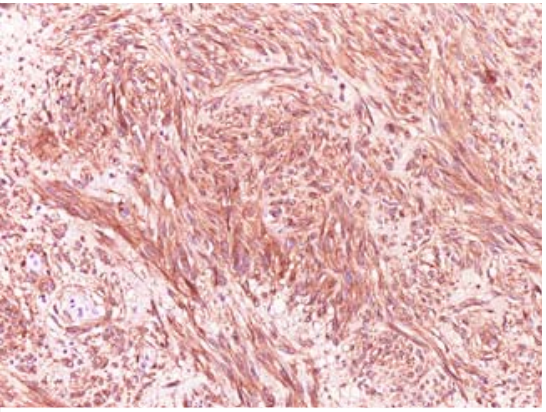

- Fig. 2 Tumor cells arranged in fascicles or whorls with cytological uniformity and syncytial-appearing eosinophilic cytoplasm, and with diffuse CD117 cytoplasmatic positivity.

Our case confirmed that STER is a safe and effective technique for removal of gastric GIST and is a viable alternative to surgery [2].

Endoscopy_UCTN_Code_TTT_1AO_2AG

\section{Competing interests}

None

\section{The Authors}

Francesco Azzolini', Paolo Cecinato', Elisabetta Froio ${ }^{2}$, Romano Sassatelli ${ }^{1}$

1 Unit of Gastroenterology and Digestive Endoscopy, Arcispedale Santa Maria NuovaIRCCS, Reggio Emilia, Italy

2 Unit of Pathology, Arcispedale Santa Maria Nuova-IRCCS, Reggio Emilia, Italy

\section{Corresponding author}

\section{Paolo Cecinato, MD}

Unit of Gastroenterology and Digestive Endoscopy, Arcispedale Santa Maria NuovaIRCCS, Reggio Emilia, Italy Fax: +39-0522-295941

paolo.cecinato@asmn.re.it

\section{References}

[1] Bosman FT, Carneiro F, Hruban RH, World Health Organization; International Agency for Research on Cancer et al., eds. WHO classification of tumours of the digestive system. Lyon: IARC Press; 2010

[2] Chen T, Zhang C, Yao LQ et al. Management of the complications of submucosal tunneling endoscopic resection for upper gastrointestinal submucosal tumors. Endoscopy 2016; 48: 149-155

\section{Bibliography}

DOI https://doi.org/10.1055/s-0043-111710

Published online: 14.6.2017

Endoscopy 2017; 49: E193-E194

(c) Georg Thieme Verlag KG

Stuttgart · New York

ISSN 0013-726X

\section{ENDOSCOPY E-VIDEOS}

https://eref.thieme.de/e-videos

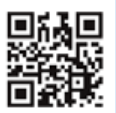

Endoscopy E-Videos is a free access online section, reporting on interesting cases and new techniques in gastroenterological endoscopy. All papers include a high quality video and all contributions are freely accessible online.

This section has its own submission website at https://mc.manuscriptcentral.com/e-videos 